\title{
El Derecho como tema literario \\ Discurso de incorporación a la Academia Peruana de la Lengua
}

Fernando DE TRAZEgNIES Granda

\section{Introducción}

Me siento confundido al iniciar este discurso de incorporación a la Academia Peruana de la Lengua porque, después de haberme interrogado en forma exhaustiva sobre los méritos que supuestamente debiera tener para recibir una distinción tan grande, no he encontrado ninguno que la justifique. Y por eso he estado tentado de comenzar estas palabras parafraseando una hermosa frase del doctor Luis Jaime Cisneros y decirles que «no se trata sino de un generoso error de parte de la Academia».

Sin embargo, una vez designado por sus votos e invitado a ocupar un asiento en el seno de este selecto grupo, tampoco parece lógico ni justo que yo me esfuerce hoy día en demostrarles que se trata de una equivocación. Por eso, acepto con modestia el juicio de los señores académicos y les agradezco muy vivamente este honor que considero entre los más altos que he recibido en mi vida.

Y quiero agradecer muy especialmente al doctor Estuardo Núñez por haber tenido la gentileza de aceptar el encargo de pronunciar el discurso de recepción. Debo confesar que me siento particularmente halagado por el hecho de ser recibido por un académico de la talla del doctor Núnez.

En realidad, acepto esta invitación a pertenecer a la Academia no como reconocimiento a mérito alguno sino como un compromiso para intentar en el futuro estar a la altura de la generosidad y benevolencia de la que he sido objeto por parte de los señores académicos, generosidad que los ha llevado a penetrar en el fondo del alma de un prosaico abogado y a descubrir, apartando papeles con sellos oficiales y códigos amarillentos por el uso, que bajo esa maraña legal se escondía, como un secreto celosamente guardado, un humilde pero apasionado amor por la lengua y la Literatura. 
En verdad, desde muy niño he tenido una inclinación marcada por la perspectiva literaria. Si bien siempre he padecido de una curiosidad multifacética y me he interesado con fervor en cosas tan disímiles como la astronomía y la historia medieval, la matemática, la filosofía oriental y la sociología política, creo que la Literatura ha sido para mí un punto de vista no declarado sobre el mundo, que me ha ayudado a comprender muchas cosas que no hubiera percibido de otra manera. Recuerdo que en el colegio, aun cuando estaba muy contento con las sutilezas del álgebra y con los experimentos de química, mi mayor satisfacción era hacer las composiciones de Literatura. Mientras que el resto de los cursos ponía en acción mi capacidad de razonamiento, escribir un pequeño ensayo de dos páginas para el curso de Literatura movilizaba mi ser entero, tanto mi razón como mis emociones y afectos; por eso me interesaba y me entretenía más; me hacía sentirme más pleno, más completo.

Todavía recuerdo algunas de mis primeras composiciones. Particularmente una, en cuarto o quinto de primaria, para la cual el profesor nos había propuesto describir con nuestras propias palabras la escena que se nos acababa de leer de la Iliada, en la que Héctor se despide de su esposa Andrómaca y de su hijo para cruzar las murallas de Troya y salir a pelear un duelo irremisiblemente fatal con el invencible Aquiles. Recuerdo que lloré sobre el papel mientras narraba la triste despedida. Hubiera querido cambiar la historia, hubiera querido escribir que Héctor no aceptaba el duelo y que prefería la vida y el amor de su esposa y de su hijo a la gloria de la muerte. Pero lloré porque comprendí que eso era imposible; comprendí que el honor está por encima de la vida y del amor; comprendí que el bien de su patria no le permitía otra cosa. Lloré de tristeza y de impotencia, porque me di cuenta ya entonces de que ni aun el autor puede fungir de Dios, ni aun el autor es dueño absoluto de sus personajes, sino que, como sucede con los hijos, una vez creados ellos imponen su propia lógica y hacen su propia vida, independientemente de lo que el escritor hubiera querido hacer de ellos.

Durante esos años escolares escribí mucho, tanto como tarea para mis cursos como también de manera gratuita, por puro entretenimiento personal. Más tarde, entré a la universidad y, con el prejuicio de que es necesario estudiar cosas con las cuales se pueda uno después ganar la vida, decidí seguir Derecho. Y, claro está, una vez comprometido con el Derecho, mi natural curiosidad y mi enfermiza facilidad para el entusiasmo hizo que lo estudiara con mente suficientemente abierta como para ilusionarme con su rigor, con su ingenio, con la perspectiva tan dramática y aguerrida que ofrecía de la vida. De alguna manera, el Derecho parecía combinar dos de mis viejas aficiones: la lógica de la matemática y la sensibilidad de las humanidades. 
Sin embargo, en esos tiempos de transición de amores intelectuales, hubiera podido suceder que mi vieja afición literaria naufragara. Felizmente, en la entonces Facultad de Letras por la que todos los futuros abogados teníamos que pasar, encontré a un verdadero maestro que me hizo conocer lo que era propiamente la vida universitaria, y sin intentar desviarme de mi camino jurídico, supo mantener viva dentro de mí la llama literaria. Este maestro, a quien quiero rendir público homenaje el día de hoy y expresarle mi agradecimiento por todo lo que he recibido de sus enseñanzas tempranas, sucede que por coincidencia es hoy el presidente de la Academia Peruana de la Lengua, el doctor Luis Jaime Cisneros.

He comentado con muchas personas de mi generación la influencia que Luis Jaime Cisneros ejerció sobre nosotros; y todos concuerdan que fue para quienes recién nos asomábamos a la vida universitaria el modelo de lo que era un académico, de lo que era un intelectual. Aprendimos muchísimo de su fina inteligencia, de su erudita formación, de su extraordinaria capacidad para movilizar nuestras curiosidades intelectuales, de su afilado sentido del humor. Pero aprendimos también de su cálido afecto, de su permanente disposición para atender las inquietudes efervescentes de una juventud bullanguera e insistente. Quienes tuvimos la suerte de contar con su amistad personal, pudimos gozar con las conversaciones -más informales pero todavía más estimulantes, más motivadoras- en la biblioteca de su casa en Miraflores, donde nos reuníamos el grupo de alumnos de cabeza agitada que adolecía de una afición calenturienta a la Literatura. En todo momento nos alentaba y, al mismo tiempo, nos centraba; nos motivaba pero no tenía concesión alguna a la mediocridad o a la sensiblería. Recuerdo muy claramente una oportunidad en la que, a mis dieciocho años de edad, le llevé unos versos. Los leyó con atención, me hizo varios comentarios útiles y luego me dijo: "No está mal. Pero vamos a esperar un tiempo. Tráeme los versos que escribas cuando ya no estés enamorado."

Al lado del Maestro, y como consecuencia de su entusiasmo, se formó un grupo de alumnos mayores que se encargaban de continuar en el patio del local de la Plaza Francia y en los cafés cercanos a la Universidad la discusión interminable sobre los temas propuestos por Cisneros; discusión que los recién llegados escuchábamos con timidez reverencial. Ésta fue la época en que descubrimos la prosa exquisitamente sencilla de Borges. Ésta fue la época también en que, un poco a espaldas de Luis Jaime Cisneros, leíamos y releíamos sin descanso a Hesse y queríamos seguir la aventura espiritual de Siddharta, convencidos de que a los cincuenta años seríamos tan excéntricos y marginales como el Harry Haller de El lobo estepario. 
La vida impone sus propios caminos, y el verdor de los cuentos cortos, de los poemas de juventud y de alguna que otra idea de una novela, fue quedando sepultado por las hojas de otoño de los expedientes judiciales, las minutas notariales y los informes legales. Sin embargo, la llama del arte no se extingue nunca una vez que ha sido encendida. Y, un poco subrepticiamente, un poco introvertidamente, el abogado ha intentado con timidez seguir fiel a su viejo amor literario.

\section{El Derecho como tema literario}

Es por ello que hoy quisiera maridar de alguna forma el Derecho y la Literatura, con la seguridad de que esta unión alquímica dará nacimiento a una perspectiva diferente de las cosas que enriquecerá las relaciones humanas.

En tiempos recientes ha habido un interés cada vez mayor respecto de las vinculaciones entre el Derecho y la Literatura. En los últimos años hemos visto aparecer varios libros que traían la clara intención de juntar lo que aparentemente era inconciliable ${ }^{1}$. ¿Acaso Disraeli no dijo alguna vez que el Derecho lo deprimía mientras que la Literatura lo exaltaba? ¿Qué tiene que ver el arte con la administración de las relaciones sociales? ¿En qué medida el Derecho puede contribuir a la Literatura y de qué forma la Literatura puede abrirle los ojos al Derecho?

En verdad, existen numerosos puntos de contacto entre las dos disciplinas, muchos más de los que usualmente se reconocen recíprocamente.

Es importante señalar que tanto el análisis literario como el análisis jurídico se preocupan fundamentalmente por el inquietante problema de la interpretación y por el papel de la intención del autor o legislador en la lectura posterior del texto. Derecho y Literatura han seguido una evolución similar en este aspecto, aun sin conocerse uno y otro y casi sin respetarse: los juristas no les daban importancia a los críticos literarios en esta materia porque consideraban que no se ocupaban de cosas «serias" sino de historias imaginadas; en cambio, los críticos literarios consideraban que los juristas tenían un nivel muy pedestre de interpreta-

Vid., entre otros, Ephraim LonDON (ed): Thre World of Law, I: The Law in Literature, II: The Law as Literature. Simon and Schuster. New York, 1960; Richard A. POSNER: Law and Literature. A Misinderstood Relation. Harvard University Press. Cambridge, U.S.A. 1988; Daniel J. Kornstein: Kill all the lawyers? Shakespeare's Legal Appeal. Princeton University Press. New Jersey, 1994. En la bibliografía peruana sobre el tema, véase Maruja BARrug: La ley es la ley. La justicia en la literatura peruana (antología). CEDYS. Lima, 1980. 
ción que no podía servir de modelo al estudio de la obra literaria. Sin embargo, estamos ante historias paralelas: la interpretación clásica tanto del Derecho como de la Literatura estuvo basada en la intención del autor; y la interpretación moderna tanto del Derecho como de la Literatura proclaman la muerte del autor ${ }^{2}$ y la del legislador ${ }^{3}$, a fin de permitir que el texto tenga valor por sí solo.

De otro lado, no es exacto que sólo la Literatura se valga de metáforas. El Derecho hace uso de ficciones, que son una forma de metáfora; y llega al extremo de crear un mundo metafórico en el que se puede hablar de una tradición o entrega ficta que no es una entrega en absoluto o de una propiedad intelectual que es más una construcción mental que una verdadera propiedad. Pero, en ambos casos, tanto en la metáfora literaria como en la ficción legal, se trata de dar cuenta de la realidad con instrumentos mejores que con la descripción directa de las cosas; porque la ficción muchas veces es más real que la propia realidad.

También vale la pena señalar que la Literatura utiliza continuamente préstamos legales para expresar situaciones no legales. Es así como se vale de motivos jurídicos para dar cuenta de situaciones ajenas a la práctica del Derecho: todos conocemos la frecuencia con que las obras literarias utilizan expresiones tales como "prenda" de amor o corazón «hipotecado", $\mathrm{u}$ otras similares, que responden claramente a la técnica jurídica.

Pero yo quisiera referirme hoy en particular a la relación entre Derecho y Literatura en materia de temas.

El Derecho, en la medida que gobierna los grandes aspectos de las relaciones humanas, se ocupa de situaciones que presentan la variedad y la tensión de la vida misma. Basta revisar cualquier colección de jurisprudencia para encontrar un sinnúmero de argumentos de novelas apasionantes. Los casos judiciales presentan drama, conflicto y suspenso; de manera que muchas veces han jugado un papel similar al teatro como espectáculo comunal. Y recientemente, tratándose de juicios muy sonados, la televisión se ha encargado de convertirlos en espectáculos universales.

A su vez la Literatura, que pretende siempre penetrar profundamente en la humanidad del hombre, se encuentra a menudo con situaciones jurídicas. Y es así como podemos advertir que existe una gran cantidad de obras literarias - particularmente novelas, piezas de teatro y libretos

\footnotetext{
2 Roland BARTHES: "La mort de l'auteur", en Le bruissement de la langue. Essais critiques $I V$. Editions du Seuil. Paris, 1984.

3 Fernando de Trazegnies Granda: "La muerte del legislador", en Revista Jurídica del Perú. Trujillo, abril-junio 1995.
} 
de cine y televisión- que tienen como tema al Derecho o que involucran de alguna manera un cierto tratamiento jurídico de la anécdota.

A veces la Literatura trata el Derecho no como un objeto de interés en sí mismo, sino como un instrumento de la narración o como una metáfora para decir otras cosas. Pero otras veces, la reflexión sobre el Derecho mismo ocupa un aspecto central de la obra literaria.

Sin embargo, aun cuando la Literatura reflexione directamente sobre el Derecho no lo hace desde un punto de vista técnico o positivista ni pretende normar una situación, sino que manifiesta más bien un interés por la justicia. En realidad, hay que distinguir entre, de un lado, los problemas legales concretos que requieren una solución técnica y normativa y que pertenecen al campo del abogado, y, de otro lado, los aspectos más generales del Derecho que se refieren a las condiciones de legitimidad, equidad, justicia, que muchas veces son materia también de análisis por otras disciplinas y que la Literatura asume como parte de las bases profundas del ser humano. La Literatura, como todo arte, debe tratar aspectos que son universales; $y$ si bien el Derecho es diferente en cada pueblo y en cada época -personalmente no creo que exista una noción universal de Derecho-, por lo menos es universal la necesidad de organizar pacíficamente la solución de conflictos y de legitimar, tanto lo que la sociedad reconoce que corresponde a cada persona (derechos), como la solución que se invente para cada conflicto. Esta necesidad de legitimación se cumple a través de lo que pudiéramos llamar «justicia», para darle un nombre cualquiera. Por tanto, aunque el Derecho no es universal, la necesidad de justicia sí lo es, sin perjuicio de que se entienda por justicia cosas muy distintas según las culturas.

No es posible, dentro del marco de este discurso de incorporación, analizar todas las obras en las que se hace una referencia al Derecho. Cervantes, Dickens, Shakespeare, Rabelais, Lewis Caroll, Guy de Maupassant, Jack London, Pirandello, Anatole France, Mark Twain, Balzac, Flaubert, Chejov, Dostoiewski, Faulkner, Kafka, Camus, Ciro Alegría, Manuel Scorza, Julio Ramón Ribeyro, José María Arguedas, Enrique López Albújar, y muchos otros, se han visto tentados de incursionar literariamente por los campos del Derecho. Quisiera limitarme a mencionar ciertos ejemplos que me parecen particularmente significativos, con la idea, sobre todo, de saber cómo los escritores perciben el Derecho.

Es sabido que las referencias a la justicia en las obras literarias son bastante antiguas. Recordemos que Sófocles hace que Antígona se enfrente a Creonte, rey de Tebas, discutiéndole su derecho de legislar. Cuando Creonte le pregunta cómo se ha atrevido a infringir sus leyes enterrando el cadáver de su hermano a pesar de que él, Creonte, había orde- 
nado que quedara sin sepultura, ella contesta: «Porque no fue Zeus quien promulgó ese edicto; ésas no son las leyes establecidas por la Justicia y por los dioses para gobernar a los hombres; $y$ yo no puedo pensar que tus leyes tengan tanta fuerza como para que puedan derogar las leyes no escritas e infalibles del cielo. Porque esas leyes celestiales no son de hoy ni de ayer, sino de siempre; $y$ ningún hombre sabe cuándo entraron en vigencia." ${ }^{4}$. Muchas veces se ha pretendido que hay aquí un planteamiento inicial de la noción de Derecho natural, entendido como leyes superiores a las humanas, que pueden legitimar o invalidar las leyes positivas. El punto es discutible y hay quienes sostienen más bien que Antígona está aludiendo a los vínculos entre hermano y hermana y afirmando simplemente que las relaciones de sangre pasan por encima de las relaciones políticas. Pero, sea como fuere, no cabe duda de que hay aquí un enfrentamiento temprano entre dos concepciones del Derecho: una según la cual el poder político puede dar cualquier tipo de leyes, y otra según la cual el poder político está limitado por ciertos principios que pueden ser considerados como un Derecho divino, como un Derecho natural o simplemente como parte de las costumbres de un pueblo.

Pero si bien han existido siempre en las obras literarias elementos que pudieran ser atribuidos al Derecho, estas referencias van a ser mucho más definidas y frecuentes a partir de la modernidad.

Milan Kundera ha sostenido que la novela es un producto de la modernidad y sitúa el inicio del género en El Quijote. Para Kundera, el creador de la Edad Moderna no es solamente Descartes, sino también Cervantes ${ }^{5}$. En realidad, es difícil atribuir la paternidad de la Edad Moderna a un autor o incluso a una actividad del ser humano, porque los horizontes culturales son producto de una gran diversidad de factores que interaccionan entre sí. Pero de lo que no cabe duda es que la novela y el propio Cervantes son hijos de la modernidad y expresiones de ella. De la misma manera, el Derecho -en el sentido que lo conocemos hoy, es decir, como fenómeno autónomo, independiente de la religión, distinto de la moral y de las costumbres sociales-es también un producto de la modernidad. Por eso es que quizá a partir del siglo XVI vamos a encontrar una presencia mayor del Derecho en la Literatura, en la medida que ésta identifica la aparición del Derecho como una nueva forma social y lo convierte en objeto específico de la intriga que nos describe.

En El Quijote, el tema del Derecho aparece sobre todo a través del episodio en el que, para seguir adelante la burla, se nombra a Sancho 
Panza como gobernador de la llamada Ínsula Barataria. Sin embargo, en este delicioso capítulo, no encontramos todavía propiamente una reflexión sobre la naturaleza del Derecho, sino la aplicación de una justicia salomónica; y por esta expresión debe entenderse no tanto una puesta en cuestión de los principios para juzgar sino simplemente una cierta habilidad o ingenio del juzgador para establecer la prueba de los hechos.

El caso típico de la justicia impartida por Salomón es el de las dos mujeres que reclaman al mismo niño como hijo. Como puede apreciarse, no hay aquí un enfrentamiento o controversia en materia propiamente legal, no hay una discusión sobre la concepción del Derecho, sino una dificultad para establecer el hecho de la maternidad: determinado factualmente quién es la verdadera madre, el problema queda resuelto. Y Salomón recurre a la estratagema de ordenar que se parta al niño en dos y se le dé un pedazo a cada reclamante. Pero Salomón sabía que la verdadera madre estaría dispuesta por amor a sacrificar el placer de tener al niño consigo y a aceptar que sea entregado a la falsa pretendiente sólo para salvar la vida del niño. Es así como Salomón descubre quién es la verdadera madre y soluciona el caso ${ }^{6}$.

En El Quijote, Sancho Panza se enfrenta con el mismo tipo de problemas de probanza durante su presunta administración de la Ínsula Barataria; y utiliza recursos muy similares a los de Salomón para solucionarlos.

Quizá el caso más claro en este sentido es el de la mujer que pretende haber sido violada. Como se sabe, un ganadero rico que vuelve de vender sus cerdos se encuentra con una mujer y le propone yogar juntos. Ella acepta y el ganadero le paga lo suficiente. La mujer, al ver que es rico, le pide más; pero como él no quiere pagarle una suma que considera excesiva por el servicio, la mujer lo trae hasta la corte del gobernador acusándolo de haberla violado: «Señor gobernador de mi ánima -le dice a Sancho Panza-, este mal hombre me ha cogido en la mitad de ese campo y se ha aprovechado de mi cuerpo como si fuera trapo mal lavado, y jesdichada de mí! me ha llevado lo que yo tenía guardado veintitrés años ha, defendiéndolo de moros y de cristianos, de naturales y extranjeros, y yo siempre dura como un alcornoque, conservándome entera como la salamanquesa en el fuego o como la lana entre las zarzas, para que este hombre llegase ahora con sus manos limpias a manosearme."

Sancho Panza pidió al ganadero la bolsa donde guardaba todavía veinte ducados y, ante el asombro de éste, se la entregó a la mujer. Ella se deshizo en agradecimientos y se fue. Pero inmediatamente Sancho Panza or-

Sagrada Biblia. «Reyes», 3, 16-28. 
denó al ganadero que la siguiera, le quitara por la fuerza la bolsa y la trajera a la corte. Al cabo de unos minutos se presentaron ambos, la mujer y el ganadero; pero la mujer seguía aferrada a la bolsa que guardaba en su regazo, debajo de la falda, sin que el ganadero hubiera podido tomarla. Entonces Sancho Panza cogió la bolsa con los veinte ducados y la devolvió al ganadero, dando por terminado el pleito. Y explicó su decisión a la mujer con estas palabras: «Si el mismo aliento y valor que habéis demostrado para defender esta bolsa, le mostrárades, y aun la mitad menos, para defender vuestro cuerpo, las fuerzas de Hércules no os hicieran fuerza." Quedaba en esa forma probado que no podía haber sido violada por ese individuo y que ella tenía que haber consentido en yogar juntos.

Como puede verse, la estructura del problema se basa en la dificultad de la prueba, como en el caso citado de Salomón, ya que de lo que se trataba era de saber cuál de los dos estaba mintiendo; y mediante una estratagema ingeniosa, al igual que Salomón, Sancho Panza descubre que es la mujer quien no dice la verdad.

Pero quizá lo que más nos interesa es encontrar en la Literatura, no tanto ingeniosas formas de probar hechos, sino la visión que tiene el escritor respecto del Derecho, es decir, acceder a concepciones y perspectivas del Derecho con la ayuda de la visión literaria.

Hacia la misma época de El Quijote, vamos a encontrar en la Literatura española un caso mucho más inquietante para el Derecho, porque lo muestra impotente para restablecer el equilibrio social. Me refiero a Fuenteovejuna, la conocida obra del Príncipe de los Ingenios, don Félix Lope de Vega.

Fernán Núñez de Guzmán, comendador de la Orden de Calatrava, ejercía el señorío sobre el pueblo de Fuenteovejuna. Hombre despótico, abusaba de sus vasallos y particularmente usaba a su antojo a las mujeres de la villa. Es por ello que los vasallos, alentados por las propias mujeres, deciden darle muerte. El rey Fernando el Católico manda un juez al pueblo para que castigue con todo rigor a los autores del crimen. Sin embargo, el interrogatorio del magistrado fracasa porque, a pesar de los tormentos, los habitantes de la villa, incluyendo a ancianos, mujeres y niños, responden simplemente que el comendador fue muerto por todos al mismo tiempo; de modo que resulta imposible individualizar a los culpables. En estas circunstancias, la alternativa es dramática y manifiestamente insatisfactoria desde el punto de vista judicial: o se declara que no existen culpables, a pesar de que ha habido crimen, o se aplica la pena de muerte a todos los habitantes del pueblo. Los Reyes Católicos, ante las noticias de los atropellos del comendador y la promesa de fidelidad de los habitantes de la villa, otorgan un indulto general. 
En realidad, estamos aquí frente a un proceso histórico-político de fin de la feudalidad en España, que abre paso, de un lado, a un moderado poder popular, $y$, de otro lado, a una incipiente modernidad que se expresa como afirmación del Poder central. Los Reyes Católicos dan inicio a una primera unificación administrativo-política del país, con miras a acabar con la desarticulación del Estado medieval.

Lo interesante es que el Derecho se encuentra en el ojo de esta tormenta política; pero lo grave es que el Derecho fracasa dos veces ante tal situación. En primer lugar, los habitantes de la villa no pueden utilizar el Derecho para contrarrestar los abusos del comendador y se encuentran forzados a hacer uso de la violencia; en segundo lugar, el rey no puede recurrir al Derecho para restablecer el orden y se ve obligado a dar una medida política, como es el indulto, a fin de normalizar las cosas. Lope nos da cuenta, pues, quizá de una manera un poco intuitiva, que el Derecho, para funcionar de manera eficiente, requiere las condiciones de la modernidad; es decir, el apoyo de un Poder político central fuerte que garantice el cumplimiento de las reglas, aun contra las autoridades, y, simultáneamente, una cierta aceptación popular, un respaldo de la población, ya que una justicia que sancionara a todo un pueblo sería -paradójicamente- una justicia injusta.

No cabe duda de que uno de los espíritus literarios más perspicaces en cuanto se refiere a la naturaleza del Derecho fue William Shakespeare. Según se sabe, su padre estuvo involucrado en varios procesos judiciales que marcaron definitivamente al escritor. El mismo William Shakespeare inició algunos juicios menores en su juventud. Luego participó en juicios como testigo. $\mathrm{Y}$ dos de sus hijas se vieron envueltas en procesos judiciales complicados: en un caso, por adulterio; y en el otro, porque el marido de una de ellas había embarazado a una tercera mujer. Por consiguiente, la experiencia judicial de Shakespeare no es despreciable?

Shakespeare recurre varias veces en sus obras a los problemas del Derecho. Quisiera solamente mencionar tres referencias particularmente notables.

La primera tiene que ver con ese tópico tan complicado que relaciona el orden con la legalidad. A este respecto, hay una obra que es poco conocida en sí misma, Enrique VI, pero que ha pasado a la historia fundamentalmente por una de sus frases: aquella en la que un personaje propone: «Primero, ¡matemos a todos los abogados!»"

\footnotetext{
Vid. Daniel J. Konnstein: Kill all the Lawyers? Shakespeare's Legal Appeal. Princeton University Press. New Jersey, 1994, pp. 15-21.

8 William ShakespeAre: Henry VI. Parte II, escena 4.
} 
En realidad, la obra trata de una revuelta popular contra el rey, promovida y manipulada por el duque de York. Jack Cade se levanta en armas y pretende realizar una suerte de utopía, redistribuyendo la riqueza y aboliendo la propiedad. La propuesta político-jurídica de Cade es manifiestamente totalitaria: asume el Derecho y la fuerza de la ley como autoridad suprema; promueve la desaparición de los bienes privados $\mathrm{y}$, con ellos, de todos los derechos individuales; de manera que la sociedad se convierte en una comunidad de derechos administrados autoritariamente por el rebelde que pretende nombrarse a sí mismo como rey todopoderoso.

Un ejemplo nos puede dar idea del desprecio del aprendiz de tirano por los derechos individuales. Cuando Cade se proclama como autoridad rebelde se da el título de Lord Mortimer y decreta que todos están obligados a llamarlo de esta manera. Instantes después entra uno de sus soldados, que obviamente no conoce este nuevo decreto, y lo llama como siempre, por su nombre usual plebeyo. Inmediatamente Cade ordena que lo maten en el sitio?. Por otra parte, sus secuaces le dan la autoridad de aplicar e interpretar las leyes de Inglaterra. Pero él contesta que si son esas las leyes que tiene que aplicar, va a ser un Derecho dolorido; y otro de sus partidarios agrega que se estarían usando leyes apestosas. Entonces Cade da una orden que equivale a renunciar al Derecho y a las leyes: «Quememos todos los registros del reino! Mi boca será el Parlamento de Inglaterra.» ${ }^{10}$. Dentro de esta misma tónica, en todo momento Cade plantea la necesidad de matar a todos los que se le opongan, de no permitir la retirada de nadie y de ejecutar sin mayores preguntas y arrojar al Támesis a todos los que no estén con su revolución.

Es en este tipo de revolución que uno de sus más feroces seguidores, Dick el Carnicero, propone: "Primero, hay que matar a todos los abogados.» Y Cade le contesta: «Sí, eso es lo que me propongo hacer. ¿No es una cosa lamentable que con la piel de un inocente cordero se haga un pergamino y que sobre ese pergamino se escriba apresuradamente una sentencia que puede destruir a un hombre? ${ }^{11}$.

Ahora bien, dentro de este contexto la famosa frase no es un ataque a los abogados sino un reconocimiento a su importantísimo papel social. Vemos que la muerte de los abogados, como primer punto programático de la nueva política, obedece a que esa política es totalitaria y a que los abogados constituyen un problema para llevarla a cabo porque son los

Ibidem, escena 6 .

Ibidem, escena 7 .

Ibidem, escena 2. 
defensores de un orden social libre: el revolucionario Cade pretende suprimir el Derecho en general para poder concentrar el poder de la organización social (o de la desorganización social) en manos de la autoridad revolucionaria. Los abogados, debido a su razonamiento sistemático que pretende integrar cada pieza de información, cada norma, cada situación, dentro de un todo coherente, son los enemigos radicales de quien pide que confíen en él solamente sobre la base de su palabra, privilegiando los sentimientos sobre la razón, movilizando el lado irracional de las personas. La revolución no puede tener éxito si no acaba con el orden; y el Derecho es sinónimo de orden social. Shakespeare nos está señalando que acabar con los abogados es el primer paso para instaurar una sociedad totalitaria.

Por consiguiente, pedir que se mate primero a los abogados, dentro de un tal proyecto político no resulta una crítica sino que es un elogio: es una forma de reconocer que los abogados son los pilares de un orden equilibrado, de una práctica sistemática y coherente de las relaciones sociales y, en última instancia, que los abogados son las bases de una sociedad libre organizada en función del ejercicio de los derechos individuales.

Shakespeare no se limita a establecer la importancia del Derecho para la organización de la sociedad sino que en otras obras se plantea cuestiones muy serias sobre la naturaleza misma del Derecho y los fines sociales que puede cumplir.

En Medida por medida, plantea dos interrogantes que aún ahora nos perturban: de un lado, ¿puede el Derecho imponer el bien o debe limitarse a impedir el mal?; de otro lado, ¿cómo manejar la corrupción de la administración de justicia?

Vicente, el duque de Viena, decide poner en práctica algunas leyes que habían caído en desuso. Durante catorce años no habían sido aplicadas, y dice Shakespeare que eran como enormes leones que hacía tiempo que no salían de su cueva para buscar presas. Nadie ha exigido su cumplimiento durante todo ese tiempo y las leyes que carecen de la coerción adecuada pierden su valor real: cuando no se usa el terror, agrega Shakespeare, la vara de la justicia resulta más motivo de burla que de temor. "Así -dice el duque de Viena-, nuestros decretos, que imponen la muerte como pena, están a su vez muertos; y la libertad ha tomado a la justicia por la nariz. El bebe golpea a su ama; y el decoro desaparece sesgadamente. ${ }^{12}$.

12 William Shakespeare: Medida por medida. Acto I, escena 3. 
Para restablecer las leyes que él mismo no ha aplicado, simula ausentarse de la ciudad y le encarga el Gobierno a Ángelo, dándole poderes omnímodos. Pero estas leyes tenían por objeto imponer una cierta moralidad. Una de estas leyes disponía que hacer el amor fuera del matrimonio daba lugar a la pena de muerte. Y Ángelo decide aplicar esa ley contra Claudio, que ha embarazado a su novia Julieta. Ante la posibilidad de que Claudio sea ejecutado en aplicación de tal ley, su hermana Isabel va a implorar la misericordia de la autoridad. Pero Ángelo se nie$\mathrm{ga}$, arguyendo, con muy buenas razones, que la ley puede ser dura pero tiene que ser cumplida; y aun cuando no se ha aplicado a nadie en los últimos años, eso significa solamente que estaba dormida pero no muer$\mathrm{ta}^{13}$. Este tipo de razonamiento nos suena muy familiar en las épocas actuales, a pesar de su perversidad intrínseca, debido a la influencia del positivismo: ninguna ley se deroga sino por otra ley; por consiguiente, el desuso es una situación de hecho y no de Derecho, por lo que una ley no pierde su vigencia formal aunque no haya sido aplicada en años. Todo esto nos suena muy moderno y aceptable desde el punto de vista de la teoría general que informa el Derecho actual.

Sin embargo, Isabel se va a encontrar con una sorpresa. Después de que el rigorista Ángelo ha insistido en que la ley que ordena la ejecución de Claudio está vigente y debe ser aplicada, éste le propone que perdona a su hermano si ella acepta hacer el amor con él. El duque, que disfrazado de monje se pasea por la ciudad y se ha enterado de todo esto, le dice a Isabel que acepte pero sólo para tender una trampa a Ángelo. En efecto, Isabel contesta a Ángelo que está de acuerdo, pero que tiene que ser a oscuras y rápido; y, en vez de ir ella a la cita, el duque envía a Mariana, que era una joven a quien Ángelo le había prometido matrimonio y no había cumplido. Al día siguiente, el duque hace su entrada pública en la ciudad, desenmascara a Angelo y le advierte que ahora él ha incurrido en el mismo delito que Claudio, y además en corrupción de la justicia, por lo que debería ser sancionado. Finalmente, el duque perdona tanto a Claudio como a Ángelo a condición de que se casen con sus respectivas prometidas con las que han tenido relaciones sexuales.

El problema de la corrupción de la justicia es casi consubstancial al alma humana: el poder -y la administración de justicia es un poderconstituye una tentación demasiado grande para el abuso. Lamentablemente, la corrupción no es ajena a nuestra justicia de hoy en día en el Perú; $y$ en los años pasados se han producido en el Perú casos bastante 
similares a la propuesta de Ángelo a Isabel. Pero esta pieza de teatro plantea otro gran problema más de fondo y que ha sido largamente discutido en la filosofía del Derecho: ¿pueden las leyes obligar a los hombres a ser buenos, dentro de la concepción del bien que tiene el legislador? O, dicho en otros términos, ¿puede la ley imponer lo que el legislador considera un bien si el pretendido beneficiario no lo considera así? ¿O es que quizá el Derecho debe limitarse a intervenir en los casos en los que la conducta de una persona atenta contra los derechos de otra?

John Stuart Mill, desde una posición liberal, plantea que, tratándose de personas mayores y con el discernimiento necesario, el Derecho no debe inmiscuirse cuando la conducta de tales personas no afecta los intereses de ninguna otra y se hace por su propio gusto: "En tales casos -dice- existe perfecta libertad para ejecutar la acción y afrontar sus consecuencias. ${ }^{14}$. Y agrega: "Ni uno ni varios individuos están autorizados para decir a otra criatura humana de edad madura que no haga de su vida lo que más le convenga en vista de su propio beneficio.." ${ }^{15}$. Por eso, concluye: "La única finalidad por la cual puede el poder, con pleno derecho, ser ejercido sobre un miembro de una comunidad civilizada contra su voluntad, es evitar que perjudique a los demás. Su propio bien, físico o moral, no es justificación suficiente.» ${ }^{16}$.

El debate se encuentra abierto sobre el tema y la Literatura nos hace ver que no podemos soslayarlo porque sus consecuencias pueden ser gravísimas.

Pero, sin duda, la obra de Shakespeare que incide más profundamente en la naturaleza del Derecho es El mercader de Venecia. La historia es perfectamente conocida y sólo quisiera destacar ciertos aspectos que son muy significativos para la reflexión legal.

Antonio, que es rico mercader y armador veneciano, garantiza a su amigo Basanio frente al prestamista Shylock para que pueda obtener el dinero suficiente para pagar sus deudas y casarse con Porcia. Pero Shylock exige que la garantía consista en una libra de carne de Antonio, extraída de un lugar del cuerpo lo más cerca posible del corazón. Lamentablemente, los barcos de Antonio no regresan a tiempo de Oriente y, al vencerse el plazo, ni Basanio ni Antonio pueden pagar la deuda, por lo cual Shylock exige la libra de carne prometida. Antonio ofrece pagarle el doble del interés convenido si lo espera; lo que equivale a una tasa del $400 \%$. Pero Shylock sostiene que las promesas deben cumplirse - pacta

John Stuart Mill: Sobre la libertad. Alianza Editorial. Madrid, 1970, p. 154.

Ibidem, p. 155.

Ibidem, p. 65. 
sunt servanda e insiste en la ejecución de la obligación alternativa. Convencidos de la legalidad de esta exigencia, todos le ruegan que cuando menos sea misericordioso, incluyendo el propio Dogo de Venecia. Pero Shylock no cede en los derechos que jurídicamente le corresponden.

En realidad, vale la pena señalar que Shylock es judío y que tanto Antonio como los otros cristianos han manifestado muchas veces su desprecio por los judíos. El propio Shylock da cuenta de ello, refiriéndose a Antonio: «Odio profesa a nuestro santo pueblo y se burla, aun en los sitios más frecuentados por los mercaderes, de mí y de mis pactos y mis provechos, que él llama usura. ¡Maldígame mi pueblo si lo perdono! ${ }^{17}$. Yle dice a Antonio: «En el mismo Rialto me increpaisteis por mi manera de prestar dinero. Lo soporté encogiéndome de hombros, porque el sufrir es distintivo de mi raza... Vos que escupisteis en las barbas mías, que de vuestros umbrales a patadas me arrojáis como a can desconocido, dinero me pedís ahora. ${ }^{18}$. Y en otra parte le dice también: "Tú me llamaste perro sin tener una razón para ello; pero si perro soy, cuídate de mis colmillos. ${ }^{19}$. En general, la obra está llena de referencias a los judíos, ofensivas en términos raciales y culturales: el Dogo de Venecia no pide que comparezca el mercader sino que se haga traer al "judío" ${ }^{20}$; y cuando le insta a ser más flexible, se refiere a su actitud como una "crueldad extraña", donde lo de extraño es claramente una referencia a su carácter de judío. Graciano, un amigo de Antonio y Basanio, lo llama siempre "bárbaro judío»" Antonio hace notar: "Mira que estás arguyendo con el judío... De nada sirve suplicar a la marea que no avance, ni preguntar al lobo por qué se come al cordero y hace balar de pena a la oveja... porque lo más difícil es querer ablandar -nada hay tan duro- un corazón judío. ${ }^{22}$. Y Shakespeare le hace decir a Shylock respecto a Antonio: «Lo odio porque es cristiano; pero aún más por prestar dinero gratis, con candidez estúpida, haciendo reducir la tasa de interés en Venecia. ${ }^{23}$.

De manera que, cuando el prestamista exige esta garantía aprovechando la necesidad de Basanio y de Antonio, de alguna manera está utilizando el contrato para vengarse de las afrentas recibidas; y quizá en el fondo quiere que éstos no cumplan con la obligación para exigir la libra de carne. Por eso algunos han llegado a decir que quizá Shylock no

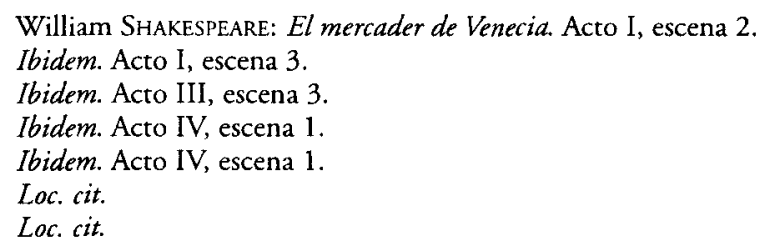


es el villano de la obra como muchas veces se ha pretendido, sino, por el contrario, una víctima del antisemitismo, que se defiende, como todas las minorías lo hacen, amparándose en la garantía que proporciona la aplicación generalizada y estricta del Derecho. En todo caso, habría por parte de Shylock, cualquiera que fuera el motivo, el uso instrumental del Derecho para realizar otros fines que no son el mero equilibrio o la mera garantía de las prestaciones contractuales. Es posible que modernamente hablaríamos de un abuso del Derecho.

No puedo dejar de expresar mi repudio por los prejuicios raciales y culturales que se plantean en esta pieza de teatro; pero en esta exposición quiero limitarme a tocar sólo los aspectos legales.

Hay, ante todo, un tema jurídico complejo que está vinculado a la doctrina de la autonomía de la voluntad contractual. Este tema se resume en los siguientes términos: ¿puede pactarse cualquier cosa en un contrato o existen ciertos límites en función de la moral, las buenas costumbres y el orden público? El Derecho peruano actual niega la disposición onerosa por vía contractual, de órganos o partes del cuerpo humano: un contrato en tal sentido es simplemente nulo. Probablemente, ninguna legislación occidental, ni en tiempos de Shakespeare ni en ningún otro tiempo, hubiera admitido una garantía semejante. Es así como se ha dicho que Shakespeare ha creado una situación jurídicamente imposible.

Sin embargo, eso no tiene importancia, porque, como hemos dicho, la Literatura plantea los grandes temas del Derecho sin tecnicismos profesionales. Por consiguiente, si lo que Shakespeare quería tratar-como personalmente pienso-era más bien el problema de la justicia frente a la interpretación de la ley, lo que le interesaba era buscar una situación marcadamente dramática que provocara la tensión necesaria para desarrollar teatralmente su idea; y para eso podía recurrir a cualquier cosa, aunque desde un punto de vista técnico no fuera legalmente válido. En el fondo, esa libra de carne humana es una metáfora literaria: podría haber sido ese dinero indispensable para evitar que sus hijos se mueran de hambre o el importe necesario para curar a su esposa de una grave enfermedad, o cualquier otro bien que se torne dramático por las circunstancias. La libra de carne constituye el puente de enlace entre la Literatura y el Derecho, que no distorsiona el Derecho sino que hace más patentes esas otras situaciones profundas de la aplicación de la ley sobre las que Shakespeare quisiera que el espectador reflexionara.

Para mí, el verdadero problema en cuestión es el que se refiere a la concepción formalista del Derecho, puesta en carne viva a la luz de una historia sobre la forma de administrar justicia y ejecutar una obligación contractual. 
Notemos, en primer lugar, la insistencia en ese carácter formalista del Derecho y en la importancia de la seguridad jurídica que el formalismo pretende realizar. Una observación, que es muy interesante y sobre la cual regresaremos, es que nadie en la obra pone en duda que el Derecho tiene que ser formalista, nadie pretende que el Derecho pueda ser otra cosa: incluso la autoridad no es capaz de ejercer su poder para liberar a Antonio de su promesa.

Shakespeare desarrolla muy bien la necesidad de respetar el texto de la ley y la palabra dada en un contrato. Ciertamente, Shylock insiste siempre en ello: "Yo exijo el cumplimiento de la ley; la pena como quedó pactada en mi escritura. ${ }^{24}$. Y cuando Porcia le sugiere que contrate un médico para que Antonio no se desangre, Shylock replica ateniéndose estrictamente al tenor del compromiso: “¿Está eso pactado en el contrato?" "No -le contesta Porcia-, pero podrías hacerlo por caridad.» Y Shylock replica: «No puedo encontrar la caridad en el texto del contrato; por tanto, no estoy obligado." ${ }^{25}$. A su vez, Graciano se queja de las leyes, pero admite que ése es el derecho de Shylock, que no puede ser desconocido: "iMalditas leyes que vivir te dejan!», le dice ${ }^{26}$. Basanio, por su parte, le pide a Porcia -disfrazada de juez- que tuerza por una vez la ley, ya que ello significaría hacer un bien muy grande a costa de un mal pequeño; pero ella, con plena conciencia de su papel de juez, contesta: "No es posible. Poder no hay en Venecia para alterar las leyes que nos rigen. Una excepción se podría aducir después como precedente; y con ese ejemplo el Estado cometería muchos errores.» ${ }^{27}$. Y ella reconoce a Shylock que su derecho es jurídicamente exigible: «Un litigio seguís de índole extraña. Pero es tal que las leyes de Venecia vuestros derechos impugnar no pueden... Pues la ley, en su espíritu y su letra, prescribe que la multa estipulada en la escritura es fuerza que se pague.» ${ }^{28}$.

El mismo Antonio, quien va a sufrir la ejecución de la garantía, admite que la ley es la ley y que los pactos deben cumplirse. Y su razonamiento es muy interesante porque es absolutamente moderno, ya que se basa en la necesidad de seguridad jurídica para el comercio, como lo plantearía Max Weber muchos siglos más tarde. No olvidemos que Venecia es una ciudad eminentemente comercial; y por ello Antonio reconoce que: «El Dogo no puede alterar el cumplimiento de la ley:

\footnotetext{
Ibidem. Acto IV, escena 1.

Ibidem. Acto IV, escena 1.

Loc. cit.

Loc. cit.

Loc. cit.
} 
dado que los extranjeros siempre han encontrado que Venecia es un lugar para hacer negocios; si se denegara la aplicación de la ley, ello afectaría la política del Estado, porque el comercio y ganancia de esta ciudad depende de todas las naciones ${ }^{29}:$ un judío era un extranjero porque no podía ser ciudadano veneciano; pero sus derechos tenían que ser respetados igual que los de un veneciano.

Aparentemente, el problema no tiene solución favorable: en cumplimiento de la ley y del contrato, Antonio debe perder su libra de carne y con ella quizá su vida. Sin embargo, Shakespeare va a encontrar un camino para salir del impasse sin afectar la noción formalista del Derecho. Porcia, la prometida de Basanio, se disfraza de juez y aparece en Venecia como si hubiese sido enviada por un famoso jurista de Padua; y, con gran inteligencia, Porcia utilizará el propio rigor legal para salvar a Antonio, llegando a voltear la situación y convertir a Shylock de acreedor en deudor, y de persona que ejerce un derecho a persona que comete un delito. Su argumento consistirá en afirmar que Shylock tiene derecho a cortar la libra de carne, pero, como el contrato sólo habla de carne, no puede derramar ni una gota de sangre. E incluso llega a la conclusión de que, como ello no es posible y necesariamente Antonio morirá, Shylock al insistir en la garantía esta premeditando un asesinato. De esta manera, Antonio queda liberado de su obligación y Shylock resulta sancionado por la ley.

Muchos comentadores han interpretado El mercader de Venecia como una apología de la equidad frente al rigor del Derecho: las leyes formales pueden resultar injustas si no son atemperadas por la equidad. De modo que, de acuerdo a este planteamiento, la equidad se encontraría más cercana a la justicia, mientras que la ley sería una suerte de trampa escrita en la que fácilmente puede perderse la justicia. La obra de Shakespeare consistiría, entonces, en un ataque fácil al legalismo.

Sin embargo, esa interpretación no me parece consistente y pienso que Shakespeare ha sido mucho más sutil; conocía más de Derecho y era mucho más ponderado que sus comentadores. En verdad, como antes he mencionado, Shakespeare no deja de ver que la aplicación estricta de la ley es de alguna manera fundamental para que los fines del Derecho puedan ser cumplidos y para que la propia justicia pueda ser servida. Sostener simplistamente la justicia frente a la positividad, la equidad frente al razonamiento jurídico riguroso, es acabar con el Derecho; porque el Derecho implica coherencia, implica generalidad en su aplicación, a fin de proporcionar seguridad. Y dentro del razonamiento de la

$29 \quad$ Ibidem. Acto III, escena 3. 
solución de Porcia no hay una consideración de justicia, de humanidad o de equidad, sino más bien una aplicación hipertécnica de las leyes positivas.

A mi modo de ver, Shakespeare ha representado en esta pieza de teatro el dilema fundamental que estructura el Derecho y que está constituido por esa antinomia entre la seguridad y la justicia, entre el orden establecido y la adaptación a las circunstancias, entre lo general y lo particular, entre la necesidad de una disciplina en la interpretación de las leyes -que respete la naturaleza sistémica del Derecho- y, de otro lado, la capacidad de abrir la ley y el pacto a través de la interpretación para dar cabida a ciertos valores sociales. Shakespeare no menosprecia en la obra ninguno de estos elementos aparentemente opuestos: ni el rigor legalista ni la imaginación. El menosprecio del rigor traería consigo el caos; el menosprecio de la imaginación creadora y adaptativa traería consigo la injusticia. En consecuencia, es preciso ser creativo dentro del orden; hay que hacer valer la justicia sin abandonar el texto de la ley o del contrato; hay que buscar el bien en lo particular sin perder de vista el bien en general. Y es así como Shakespeare orienta la solución del caso: utilizará el texto contra el texto; no abandonará el texto sino que hará uso-quizá un poco caricaturescamente- de la interpretación.

Shakespeare quiere decirnos que aun el texto más claro exige interpretaciones. El contrato hablaba de una libra de carne cerca del corazón. Pero ¿significa esto que está o no permitido derramar sangre? En realidad, hay dos lecturas posibles. De un lado, puede decirse que para cortar una libra de carne hay que derramar sangre; por lo que ese pacto incluía tácitamente el pacto de la sangre. Sin embargo, puede decirse también que el pacto se refiere solamente a carne, y que, como tomar carne sin derramar sangre es imposible, el pacto es nulo. Cada uno de los que interviene en el problema jurídico hará una interpretación.

Definitivamente, no estamos ante el triunfo de la equidad -como excepción o recurso extraordinario- sobre la justicia legal: la "misericordia" no es admitida. Se trata, más bien, del "uso estratégico" de las normas legales y contractuales dentro de un Derecho concebido como una guerra reglamentada de intereses, valores y puntos de vista.

En el siglo XX, con la crisis de la modernidad y el anuncio de una postmodernidad todavía indefinida, sobreviene también una crisis del Derecho. Este fenómeno social que había ganado su autonomía en el siglo XVI y que había sido la piedra angular de la sociedad occidental, aparentemente se desvincula a tal punto del resto de los procesos sociales, que es visto como una amenaza existencial antes que como la forma de garantizar la libertad y de estructurar la vida social. Posiblemente, las dos novelas más significativas en este sentido son $E l$ proceso de Kakfa y $E l$ 
extranjero de Camus.

En El proceso, Joseph K., un exitoso empleado de banco, es un día detenido en su domicilio por unos presuntos policías. Pregunta la razón de su arresto, pero nadie le da una respuesta. Lo llevan a un tribunal, lo juzgan inmisericordemente por un crimen que no sabe cuál es, se presentan testigos de hechos que él mismo ignora, queda en libertad provisional pero le advierten que en cualquier momento lo llamarán de nuevo, que en todo momento está siendo observado. Contrata un abogado famoso. Éste le dice que tiene información que viene del interior del propio tribunal sobre el proceso y sobre los jueces, pero que no se la puede decir porque es confidencial. El juicio sigue de manera escrupulosamente cruel y todos sus alucinantes pasos van siendo descritos con una nitidez que provoca escalofríos; pero, al mismo tiempo, hay una bruma general que rodea el proceso porque Joseph K. no tiene la más mínima idea del cargo por el cual se le acusa ni ante qué tipo de tribunal se encuentra. Finalmente es ejecutado en la ignorancia.

La novela se presenta como una angustiosa denuncia contra el Derecho como instrumento de opresión y de intimidación del ciudadano individual, como forma de dominación que utiliza el secreto, la trampa, la intimidación, para someter al hombre a los dictados de la sociedad; denuncia tanto más grave si se tiene en cuenta que Kakfa fue abogado. Muchas veces se ha dicho que El proceso es la protesta de Kafka contra el totalitarismo; y se propone que este autor se anticipó de alguna manera a las dictaduras del fascismo y del comunismo. Pero, aun cuando esa interpretación es válida a un cierto nivel, es preciso hacerle una corrección importante, o cuando menos una ampliación fundamental. Hay que tener en cuenta que esos policías, esos jueces, ese proceso al que se somete a Joseph K., no aparecen como vinculados al Estado: los policías visten de civil, el tribunal funciona en una perdida casa de vecindad, los jueces parecen más bien miembros de una organización secreta. Por eso, Joseph K. se pregunta: «¿Quiénes son estos hombres? ¿Qué autoridad representan?». Y es que, en el fondo, El proceso utiliza el Derecho para mostrar terrores mucho más primitivos y más inescapables que los de la tiranía política: es una visión angustiada, no del ciudadano sino del hombre a secas, como un ser que camina a oscuras por la vida, al cual le suceden cosas que no puede controlar, que pregunta y que no obtiene respuesta. Hay quizá una doble metáfora en todo esto: Kafka está utilizando el Derecho como metáfora de la tiranía social; pero a su vez usa la tiranía social y la política como metáfora de esa tiranía existencial del mundo y de los otros sobre la subjetividad de cada persona.

Por su parte, El extranjero de Camus resulta una de las novelas más corrosivas y cáusticas contra el Derecho, no porque lo enfrente, sino 
porque lo ignora, porque le quita fuerza a sus decisiones desde el momento en que el castigado no se siente castigado ya que le es igual que lo castiguen o no.

Mersault, el reo, es una persona totalmente neutra, que se compromete a casarse con una mujer reconociendo que hubiera podido comprometerse con cualquier otra, que mata sin estar muy seguro de la razón por la que lo hace y que, en general, adopta una indiferencia absoluta frente al mundo. Se le sigue un proceso judicial, pero no le importa mucho el resultado: que la sociedad lo mate, igualmente, a él como castigo de su crimen o que lo declaren inocente por haber sido legítima defensa, le es igual. En el fondo, el juicio que se le sigue es una farsa y Mersault va a ser sancionado, no por haber matado a una persona sino porque no se le entiende, porque es una persona totalmente ajena a los valores imperantes, porque es un extranjero en el sentido más total del término. De esta manera, la justicia aparece como una maquinaria de reforzamiento de los valores del grupo y de exclusión profiláctica de aquel que pudiera ser percibido como distinto, original, independiente: el Derecho, en vez de asegurar la autonomía individual, es una de las formas de opresión y de homogenización social, de destrucción de la individualidad.

Mersault tiene todas las características para inspirar el rechazo del lector, porque no es tampoco el individualista creador que se opone revolucionariamente a los valores establecidos sino que se limita a ejercer una resistencia inerte y gris, carente de sentimientos y de remordimiento. Pero lo extraordinario es que, a pesar de ello, Camus ha logrado que el lector adopte el partido del criminal y que más bien condene al juez y a la sociedad. Esta novela representa el rechazo más radical de la imposición de los valores establecidos, porque no se basa en la afirmación de otros valores: no es ni siquiera una negación militante, sino la mera neutralidad. La imposición es considerada opresiva sólo porque es imposición, cualquiera que sea su contenido. Mersault se convierte de criminal en víctima; y la sociedad, los jueces, el Derecho, que lo condenan a muerte, pasan a ser los asesinos.

Para Mersault, el fiscal que acusa y el abogado que lo defiende no son sino variantes de una misma posición absolutamente ajena a lo que él mismo siente y a los hechos como él los vive. Ve el juicio como un juego extraño dentro del cual él mismo no es una persona sino un mero objeto de discusión: el proceso judicial es descrito como un sistema cerrado de razonamiento, con sus tópicos, sus ritos, sus prejuicios, que excluye toda intervención auténtica del propio reo. Y si bien en algunos momentos Mersault tiene la tentación de abandonar su indiferencia y defenderse, pronto se da cuenta de que no vale la pena. Dice: «En cierto modo, 
parecían tratar el asunto prescindiendo de mí. Todo se desarrollaba sin mi intervención. Mi suerte se decidía sin pedir mi opinión. De vez en cuando tenía deseos de interrumpir a todos y decir: "Pero al fin y al cabo, ¿quien es el acusado? Es importante ser el acusado. Y yo tengo algo que decir." Pero, pensándolo bien, no tenía nada que decir.» ${ }^{30}$.

El Derecho también ha sido un tema dentro de la Literatura peruana. Sin embargo, no es tratado como una de las dimensiones de toda vida social ni cuestionado en su esencia misma, sino visto desde la perspectiva de considerarlo como una forma de explotación de los poderosos sobre los débiles: usualmente la Literatura peruana no se aproxima al Derecho desde la filosofía sino desde la sociología. Es por eso que, salvo raras excepciones, el Derecho aparece fundamentalmente en contextos campesinos y casi diría indios. Los autores describen la forma como los jueces se pliegan a los patronos y a los terratenientes para contribuir al despojo del hombre humilde del campo.

Uno de los textos clásicos en ese sentido es El mundo es ancho y ajeno, de Ciro Alegría. En una de sus páginas, el anciano Chauqui advierte a los demás comuneros sobre cómo los gamonales les arrebatan sus tierras a las comunidades y después se justifican con la ley y el Derecho: “iLa ley, el derecho! ¿Qué sabemos de eso? Cuando un hacendado habla de derecho es que algo está torcido; y si existe ley es sólo la que sirve pá fregarnos. Ojalá que a ninguno de los hacendados que hay por los linderos de Rumi se le ocurra sacar la ley. ¡Comuneros, témanle más que a la peste!» Y refiriéndose al comunero Rosendo Maqui, dice Ciro Alegría: "¿Qué significaba la justicia? ¿Qué significaba la ley? Siempre las despreció por conocerlas a través de abusos y de impuestos: despojos, multas, recaudaciones.»

En Yawar Fiesta, de Arguedas, no son los terratenientes de Lima quienes explotan a los indios con la ayuda del Derecho, sino los mistis, los mestizos que han logrado ocupar cargos de principales en el pueblo: "Año tras año, los principales fueron sacando papeles, documentos de toda clase, diciendo que eran dueños de este manantial, de este echadero, de las pampas más buenas de pasto y más próximas al pueblo.» El juez se encargaba, luego, de consagrar públicamente este despojo, explicando en quechua a los indios lo que resultaba inexplicable en justicia: "Con la ley ha probado ser dueño. Ahora puede hacer lo que quiera con sus tierras." Y si alguno protesta, al igual que a Rosendo Maqui de Elmundo es ancho y ajeno, se le abre instrucción y se le mete preso por cuatrero o invasor de tierras.

31) Albert Camus: El extranjero. Cap. IV. 
El juez y el "tinterillo" son dos personajes claves de la novela indigenista peruana. El primero es usualmente un hombre que oscila entre la debilidad y la prepotencia: debilidad frente al poderoso y prepotencia frente al débil. El «tinterillo" tiene una posición más ambigua y complicada. El "tinterillo" no es usualmente un abogado, pero funge como tal. Tiene un amplio contacto con ese misterioso mundo del Derecho occidental, pero está suficientemente cerca del comunero como para que éste pueda contratarlo profesionalmente. De esta manera, el «tinterillo» ayuda al campesino, pero, al mismo tiempo, lo explota porque le pide constantemente dinero. Por otra parte, ese "tinterillo", a cambio de favores económicos o sociales, puede ponerse del lado del terrateniente y traicionar al campesino. El tinterillo es una suerte de "desclasado" voluntario, que juega en cualquier sentido, según le convenga; pero que, al mismo tiempo, resulta una pieza clave para el acceso del indio a la justicia occidental.

Son raras las obras literarias peruanas ambientadas en las ciudades que incorporen el Derecho o la administración de justicia como parte de la trama. Y en algunos de estos casos, no se trata sino de transposiciones urbanas de la perspectiva sociológica-indigenista, como en $A l$ pie del acantilado, un cuento de Julio Ramón Ribeyro, donde los invasores de un terreno del Estado son instruidos por el juez para que abandonen sus precarias casas y se vayan a vivir donde puedan porque legalmente procede su desalojo; o en Cambio de guardia, otro cuento del mismo autor, donde el juez del trabajo es abordado en todas las formas por los empresarios para que resuelva en contra de los obreros.

\section{La Literatura como forma de conocimiento}

Quisiera concluir planteando como tesis que la Literatura no es un mero pasatiempo, no es un entretenimiento ocioso y ni aún siquiera un mero goce estético, siendo ya esto último muy importante: es también una forma diferente de conocimiento, una perspectiva única sobre la realidad.

En verdad, la Literatura moviliza no sólo la razón, sino también la imaginación y los sentimientos, lo que permite dar una visión menos rigurosa pero más cálida de las cosas: lo que se pierde en capacidad analítica se gana en poder de síntesis y en profundización del sentimiento. La Literatura no analiza el mundo, no lo convierte en cadáver para diseccionarlo con ayuda del bisturí de la razón, sino que lo siente empáticamente y nos lo presenta como un hecho vivo; nos invita a participar de él con todo nuestro ser. De alguna manera, el arte logra realizar esa unión del logos y del eros, que quería Platón. 
De esta forma, la Literatura nos dice cosas sobre el Derecho que no sería posible conocer de otra manera: viéndolo desde fuera, la Literatura nos entrega una visión viva del Derecho; frente a una consideración técnica y fría del Derecho, visto desde el propio Derecho, la Literatura lo captura para devolvérnoslo con más carne, con más humanidad.

Alguien ha dicho que sucede muchas veces que hay tanto Derecho que no queda lugar para la justicia; y que las personas perecen de arbitrariedad en medio de la razón, al igual como los marineros perecen de sed en medio del agua. Pienso que la perspectiva literaria puede contribuir a devolvernos el equilibrio y crear en los abogados la necesidad de guardar un espacio para la justicia en medio de la acumulación de códigos y leyes que usualmente tenemos en el desván de nuestra mente. 